\title{
Can Marketing and IT Be Friends? The Impact of Information Strategy, Structure, and Processes on Business Performance: An Abstract
}

\author{
Stefan Sleep and Dana Harrison
}

\begin{abstract}
The management of information is critical to customer relationship management and business performance. Marketers are increasingly becoming engaging in information management from inception or being tasked with advanced technology infrastructure decisions that will effectively collect and analyze information. To address the increasing role of information and technology in marketing strategy, the focus of this research is twofold. First, we investigate the impact of uncoordinated information management on the quality of information available. Next, we explore how behavioral (e.g., trust, power, strategic alignment), relational (e.g., collaboration), and resource (e.g., data analytics skills, data decision-making culture) elements impact the role of information governance on firm performance.
\end{abstract}

References Available Upon Request

\footnotetext{
S. Sleep $(\square)$

Georgia Southern University, Statesboro, GA, USA

e-mail: ssleep@georgiasouthern.edu

D. Harrison

East Tennessee State University, Johnson City, TN, USA

e-mail: harrisondl@mail.etsu.edu
} 